\title{
Circulating microRNA-7 regulates insulin, inflammatory and GnRH signaling pathways by targeting IRS1, IRS2, and RAF1 genes in gestational diabetes mellitus
}

\section{Ravi BHUSHAN}

Institute of Science, Banaras Hindu University

\section{Anjali Rani}

Institute of Medical Science, Banaras Hindu University

\section{Deepali Gupta}

Banaras Hindu University

\section{Akhtar Ali}

Institute of Science, Banaras Hindu University

\section{Anima Tripathi}

Department of Zoology, Banaras Hindu University

Pawan K Dubey ( $\nabla$ pkdubey@bhu.ac.in )

Institute of Science, Banaras Hindu University

\section{Research Article}

Keywords: MicroRNAs, Plasma, Tissue, Real-time PCR, Gestational Diabetes Mellitus

Posted Date: July 13th, 2021

DOI: https://doi.org/10.21203/rs.3.rs-702559/v1

License: (c) (i) This work is licensed under a Creative Commons Attribution 4.0 International License.

Read Full License 


\section{Abstract}

\section{Aims/hypothesis}

Small non-coding micro RNAs (miRNAs) are indicated in various metabolic processes and play a critical role in disease pathology, including gestational diabetes mellitus (GDM). The purpose of this study was to examine the altered expression of miRNAs and their target genes in placental tissue (PL), cord blood (CB), and maternal blood (MB) of matched non-glucose tolerant (NGT) and GDM mother.

\section{Methods}

In a case-control study, micro-RNA was quantified from forty-five serum (MB $n=15, C B n=15$, and PL $n=$ 15) and matched placental tissue using stem-loop RT-qPCR followed by target prediction, network construction and functional and pathways enrichment analysis. Further, target genes were verified in-vitro through transfection and RT-qPCR.

\section{Results}

Five miRNAs, namely hsa-let 7a-5P, hsa-miR7-5P, hsa-miR9-5P, hsa-miR18a-5P, and hsa-miR23a-3P, were significantly over-expressed $(p<0.05)$ in all three samples namely $P L, C B$, and MB of GDM patients. However, the sample-wise comparison reveals higher expression of miRNA 7 in MB while lowest in $C B$ than control. Furthermore, a comparison of fold change expression of target genes discloses a lower expression of IRS1, IRS2, and RAF1 in MB while comparatively higher expression of NRAS in MB and CB. In-vitro validation reveals lower expression of IRS1/2 and RAF1 in response to overexpression of miR-7 and vice-versa. Thus it is evident that increased miRNA7 expression causes down-regulation of its target genes IRS1, IRS2, and RAF1 in GDM mother compared to control. Further, target prediction, pathway enrichment, and hormone analysis (significantly higher FSH \& LH in MB of GDM compared to NGT) revealed the insulin signaling, inflammatory and GnRH signaling as major pathways regulated by miRNA7.

\section{Conclusions/Interpretations}

Thus, an elevated level of miRNA7 may be associated with the progression of GDM by altering the multiple pathways like insulin, $\mathrm{GnRH}$, and inflammatory signaling pathways via targeting IRS1, IRS2, and RAF1, implicating a new therapeutic target for GDM.

\section{Introduction}

Gestational diabetes mellitus (GDM) is defined as any degree of carbohydrate intolerance, with onset or first recognition during the second or third trimester of pregnancy [1]. GDM is an emerging pregnancy complications affecting approximately $1-14 \%$ of all pregnancies, with its increasing prevalence 
globally [2]. GDM has adverse health consequences (short- term as well as long-term) on the mothers and the neonates. GDM mother has a high risk of developing type 2 diabetes after term, including other pregnancy indications like gestational hypertension, diabetic ketoacidosis, and obesity. In contrast, the offspring of GDM mothers are at a higher risk of developing obesity, diabetes, and cardiovascular disease, in their adult lives [3]. Hence, proper diagnosis and therapeutic intercession are essential for lowering the risk of GDM and its associated adverse outcomes in mother as well as neonates. However, the exact mechanisms that contribute pathogenesis of GDM remain unclear. It is hypothesized that it begins due to the dysfunction of pancreatic islet cells and genetic alteration in insulin resistance, inflammation, and hormone pathways.

Recently, differential miRNA expression has been recognized as a possible contributor to many human disease progression, including GDM [4-6]. It has been shown that higher expression of miR-9 in pancreatic islets leads to decreased insulin production by down-regulation of Onecut2 and up-regulation of Rab [7]. Likewise, it is reported that MiR-7 negatively regulates beta-cell differentiation by targeting Pax 6 gene $[8,9]$. Furthermore, glucose metabolism and insulin signaling pathways were regulated through miR-33a-5p by targeting the insulin receptor substrate 2 (IRS2) genes [10,11]. Despite their classical role in mRNA interference, virtually miRNA plays a significant role in every cellular process, for example, proliferation, differentiation, apoptosis, and development. However, it is observed that over-expression or reduced expression of miRNAs (altered miRNAs) has been significantly correlated with many human diseases, including GDM $[6,12-14]$. Although, the altered miRNAs and related target genes in placental tissue (PL), cord blood (CB), and maternal blood (MB) of GDM patients have never been investigated. Further, comparative data on miRNAs expression in all three samples and its biological relevance in the case of GDM has not been studied previously and warrants further investigation.

Therefore, the current study aims to compare the expression profiles of five selected miRNAs (based on literature search) in three different samples [MB, CB, and PL] from GDM and non-glucose tolerant [NGT] women by qRT-PCR analysis. Further, target genes specific to GDM were searched and enriched for their function and pathways. Genes regulated by these miRNAs are implicated in the inflammation, insulinsignaling pathway, and gonadotrophic hormone response. Expression of target genes, namely IRS1, IRS2, NRAS, and RAF1 were further quantified by qRT-PCR. The final goal of this study was to elucidate the systemic role of miRNAs in the onset and progression of GDM and its consequences on fetal health.

\section{Methods}

\section{Patients and samples}

To evaluate the role of circulating miRNA in gestational diabetes mellitus patient we choose a casecontrol study design. The patients were attended in the Gynaecology outpatient ward of Sir Sundar Lal Hospital, Banaras Hindu University. Single-step testing was performed using $75 \mathrm{gm}$ oral glucose and measuring blood sugar 2 hours post ingestion. The threshold blood sugar level $\geq 140 \mathrm{mg} / \mathrm{dl}$ is considered as a cut-off for the GDM diagnosis, according to Maternal Health guidelines, Ministry of health and 
family welfare, Government of India. Peripheral blood was collected from 15 pregnant women with GDM and 15 pregnant healthy (NGT) age matched women at 24-34 weeks of pregnancy over a period of one year in 2019. These patients were followed to collect cord blood and placental samples at term. The Ethics Committee approved the study protocol of Banaras Hindu University. Clinical parameters related to patients and other biological parameters like $\mathrm{LH}, \mathrm{FSH}$, and $\mathrm{HbA} 1 \mathrm{c}$ were noted and summarized in Table 1. All patients had given informed consent for being included in the study.

\section{Blood and tissue samples processing}

The processing of blood and tissue samples was done according to a standard optimized protocol for miRNA and biochemical analysis. The blood was collected in BD Vacutainer serum tubes and processed within 2 hours after collection while the tissue was taken in 1X PBS solution containing antibiotics. Blood in BD Vacutainer serum tubes was left at room temperature for 1 hour to allow proper and complete coagulation. Blood tubes were then centrifuged at $2500 \mathrm{rpm}$ for 10 minutes at $5^{\circ} \mathrm{C}$. Using a $1000 \mathrm{ul}$ pipettor, serum from the top was gently isolated without disturbing or collecting any pelleted cells. Serum was properly transferred in RNAse-free tubes, labeled, and finally stored at $-80 \mathrm{oC}$ till the RNA extraction. The tissue was appropriately rinsed in saline solution to wash off the blood and finally stored at $-80 \mathrm{oC}$ with RNA later till the RNA extraction.

\section{RNA extraction}

TRI reagent (Sigma) was used to extract RNA from $250 \mathrm{ul}$ of serum and $100 \mathrm{mg}$ of tissue from each patient. The manual provided was followed to isolate RNA. For $0.25 \mathrm{ml}$ of serum, $0.75 \mathrm{ml}$ of TRI was used, while for $100 \mathrm{mg}$ tissue, $1 \mathrm{ml}$ of TRI was used. The RNA pellet was finally dissolved and stored at $80^{\circ} \mathrm{C}$. DNase I, RNase free (Thermo scientific), was used for DNA removal. 1 U DNase I, RNase free, was used for 1 ug of RNA.

\section{Quantitative RT-PCR of mature miRNAs and target genes}

The Stem-loop technique was used to quantify the mature miRNA with minor modifications. Briefly, 1ug of total RNA was used to synthesize cDNA for each miRNA. 20ul of reverse transcriptase reactions contained 10ul of 1 ug RNA, 1 X RT buffer, $0.25 \mathrm{mM}$ each of dNTPs (Thermo Scientific), 200U/ul M-MULV reverse transcriptase (Thermo Scientific), 20U/ulRNase inhibitor (Thermo Scientific), and 2ul antisense looped primer specific to each miRNA. The mix was incubated at $16^{\circ} \mathrm{C}$ for $30 \mathrm{~min}, 42^{\circ} \mathrm{C}$ for $30 \mathrm{~min}$, and $85^{\circ} \mathrm{C}$ for $5 \mathrm{~min}$. It allowed the creation of the cDNA library for miRNA. For cDNA synthesis, reaction mixture contain random hexa-primer instead of stem-loop primer and mix was incubated at $25^{\circ} \mathrm{C}$ for 5 $\min , 42^{\circ} \mathrm{C}$ for $60 \mathrm{~min}$, and $70^{\circ} \mathrm{C}$ for $5 \mathrm{~min}$. It allowed the creation of an mRNA cDNA library. Subsequently, real-time quantification was performed using the Maxima SYBR Green/ROX qPCR master mix (Thermo

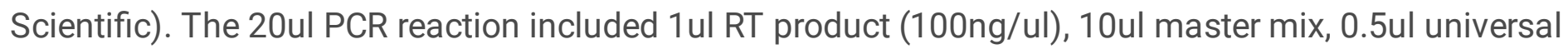
reverse primer, and $0.5 \mathrm{ul}$ sense primer. The reactions were incubated in optical strips/plates at $95^{\circ} \mathrm{C}$ for 
$10 \mathrm{~min}$, followed by 40 cycles of $95 \mathrm{oC}$ for $15 \mathrm{~s}$ and $60 \mathrm{oC}$ for $1 \mathrm{~min}$. All reactions were run in triplicate. After reactions, dCT and fold change were calculated. For relative expression value, $2^{\wedge}$-dCT was used.

\section{Enzyme-linked immunosorbent assay (ELISA)}

A glucose assay kit (ab65333) were used to measure the blood glucose levels. The FSH and LH levels were measured in blood serum using specific kits (E.lab) according to the manufacturer's instruction.

\section{Bioinformatic analysis}

Experimentally validated/ predicted miRNA target genes were searched using Targetscan Human 7.2 [15] and miRDB [16]. Genes that are common in both Target scan 7.2 (http://www.targetscan.org/vert_72/) and miRDB (http://mirdb.org/) and having target score $>95$ were extracted and considered for further analysis. Venn's diagram was constructed for common genes using the Venny tool [https://bioinfogp.cnb.csic.es/tools/venny/]. A protein-protein interaction network (genes with combined score $>0.9$ ) and miR-mRNA regulatory module (MMRM) was constructed using STRING v11.0 (https://string-db.org/) [17] and Cytoscape v 3.2.1. [18]. Gene ontology (GO) enrichment analysis including molecular function (MF), biological process (BP), and cellular component (CC) was performed for the genes present in the network using DAVID v 6.7 (database for annotation, visualization, and integrated discovery; http://david.abcc.ncifcrf.gov/) [19]. The target gene list was cross-matched with GDM related gene list available on the online database OMIM (https://www.omim.org/) and Gene Cards (https://www.genecards.org/). Relevance score was taken as criteria for the selection of GDM specific target gene for further analysis.

\section{PANC-1 cells culture and miRNA mimics/inhibitor transfection}

The human pancreatic cancer cell line, PANC-1, was purchased from the National Centre for Cell Sciences (Pune, India). PANC-1 cells were grown in Dulbecco's Modified Eagle Media (Sigma, USA) with 10\% heatinactivated fetal bovine serum (FBS, Sigma, USA). The cells were incubated at $37^{\circ} \mathrm{C}$ under a humidified atmosphere with $5 \%$ carbon dioxide. MicroRNA mimics, inhibitors, and control oligos were purchased from GeneX. Cells were grown for $24 \mathrm{~h}$ before transfection. Transfection was conducted using an electroporator (NucleofectorTM 2b Device, Lonza) following the manufacturer's protocol. In brief, Cells were cultured for $24 \mathrm{~h}$. On second day cell were collected and transfected with control oligos (NC, 10nM), miRNA-mimics $(\mathrm{M}, 10 \mathrm{nM})$, and miRNA-inhibitor $(\mathrm{I}, 50 \mathrm{nM})$. In fourth group, cells were co-transfected with mimics and inhibitor ( $\mathrm{M}+\mathrm{l}, 20 \mathrm{uM}$ both) both. Cells were harvested after $24 \mathrm{~h}$ post transfection, before harvesting imaging was performed on EVOS cell imaging systems.

\section{Statistical analysis}

To observe the significant differences in expression levels of RNA, clinical characteristics (age, BMI), laboratory parameters, and obstetric parameters, paired t-test and ANOVA analysis were applied. All subjects included in the study were age matched. Paired $t$-test was used to evaluate individual 
differences between groups, while analysis of variance (ANOVA) was used for multiple comparisons. A $p$ value $<0.05$ was considered statistically significant. Statistical comparisons were performed using Graph Pad prism 7. For correlation analysis, R v 4.0.3 software was used. Hmisc and corrplot packages were used for spearman's correlation analysis.

\section{Results}

\section{Comparison of expression of selected miRNAs in maternal blood, cord blood, and placental tissues of GDM patients compared to controls.}

In an effort to set out the comparative expression profile of selected miRNAs in three different samples, namely placental tissues $(n=15)$, cord blood serum $(n=15)$, and maternal blood serum $(n=15)$ of GDM patients, we conducted an unbiased stem-loop qRT-PCR. Blood samples from 15 healthy (NGT) women and 15 GDM mother were assessed. Those patients were followed for cord blood and placental tissue samples at term. The two groups were matched for age and other clinical parameters. Patients with higher age group were excluded from the study. The mean age and BMI of the GDM cohort were significantly higher than the NGT control cohort ( $\mathrm{p}=0.0003$ ) (Table 1).

Expression of five miRNAs, namely let7a, miR7, miR9, miR18a, and miR23a, were evaluated in all three samples, namely placental tissues $(n=15)$, cord blood serum $(n=15)$, and maternal blood serum $(n=15)$ of GDM and NGT group. The results highlighted a significantly increased expression of all five miRNAs in all three samples of GDM compared to NGT patients. Relative expression shows significant up-regulation of let $7 a(p<0.0001)$, $\operatorname{miR} 7(\mathrm{p}<0.0001), \operatorname{miR} 9(\mathrm{p}<0.0001), \operatorname{miR} 18 \mathrm{a}(\mathrm{p}<0.0001)$ and $\operatorname{miR} 23 a(\mathrm{p}<0.0001)$ in maternal blood serum $(n=15)$ (Fig. 1A-E). Similarly, in cord blood serum significant upregulation of let $7 \mathrm{a}(\mathrm{p}=0.0001), \operatorname{miR} 7(\mathrm{p}=0.0008), \operatorname{miR} 9(\mathrm{p}=0.0002), \operatorname{miR} 18 \mathrm{a}(\mathrm{p}=0.0021)$ and miR 23a ( $p=0.0001)$ was observed (Fig. 1 F-J). Like maternal blood and cord blood, all these five miRNAs, namely let $7 a(p=0.0096), \operatorname{miR} 7(p<0.0001), \operatorname{miR} 9(p=0.0037), \operatorname{miR}$ $18 \mathrm{a}(\mathrm{p}<0.0001)$, and $\mathrm{miR} 23 \mathrm{a}(\mathrm{p}<0.0001)$, were found to be significantly up-regulated (Fig. $1 \mathrm{~K}-\mathrm{O})$. Frost et al. have shown that increased global and pancreas-specific expression of Let-7a resulted in diminished glucose-induced pancreatic insulin secretion and altered glucose tolerance in mice [20]. Adult mouse and human islet cells profusely express the miR-7, further, miR 7 has been implicated in inhibiting insulin granule exocytosis [21]. Hu et al. has reported miR 9 as a negative factor of insulin secretion from beta cells of mice [22]. Wang et al. have shown the association of increased expression of mir 18a in PBMC with the risk of T2DM, while Yang et al. have shown serum miR-23a as a potential biomarker for pre-diabetes diagnosis and type II diabetes [22, 23]. Since all these miRNAs are related to either impaired glucose tolerance or type II diabetes or altered insulin synthesis and secretion, so it can be stated that their increased expression in GDM mother will be playing a role in the onset and progression of diabetes which is detrimental to both maternal and fetal health.

\section{The sample-wise comparison of miRNA expression reveals higher expression in maternal blood.}

Comparative analysis of fold change $\left(2^{\wedge}-\mathrm{ddCt}\right)$ value of each miRNA in all three samples revealed that expression level of all these miRNAs are higher in maternal blood $(n=15)$ and placenta $(n=15)$ as compared to cord blood $(n=15)$ with the highest fold change value in maternal blood $(n=15)$ while least fold change value in cord blood (Fig. 2 A-E). This gradual decrease of expression of miRNAs from maternal blood to the placenta to cord blood suggests the endocrine nature of miRNA, which are transported in a way similar to hormone from the maternal circulation to fetal circulation via the placenta and forming a gradient which is evident in their expression level (Fig. 8). A recent report has also shown the hormone-like nature of extracellular miRNA, secreted by host cells into extracellular fluids, and can be transported and taken up by recipient cells to control their activities in a 
way similar to hormone [24]. This reinforces our idea of diffusion of maternal miRNAs into the fetal circulation and affecting fetal physiology in a way hormone does; however, further experimentation is required to prove this concept.

\section{Relative fold change $\left(2^{\wedge}-\mathrm{ddCt}\right)$ analysis reveals a higher expression of miR-7 in all three samples.}

To identify the highly expressed miRNA in each sample type (MB, CB, and PL), fold change $\left(2^{\wedge}\right.$-ddCt) values of all five miRNAs were compared in each sample separately. In maternal blood serum $(n=15)$, fold change expression of let $7 a, \operatorname{miR} 7$, and miR 9 was comparatively higher than other miRNAs (Fig 2F). Fold change expression of miR 7, miR 9, and miR 23a was found to be comparatively higher in cord blood serum (Fig 2G) as well as in placental tissue (Fig 2H). Thus miR 7 and miR 9 were significantly up-regulated in all three samples of GDM as compared to NGT controls. Several studies have reported the inhibitory role of miR 7 and miR 9 in the synthesis and secretion of insulin and its interaction with receptors in other forms of diabetes like type 1 and type 2 diabetes, thus causing insulin deficiency or insulin resistance $[14,21]$. Hence it is evident that the up-regulation of miRNAs 7 and 9 in GDM will be similarly hampering insulin metabolism and causing either insulin deficiency or insulin resistance.

On the other hand, the expression of miR23a was found to be higher in cord blood $(n=15)$ and placenta $(n=15)$ than in maternal blood $(n=15)$. MIR 23 has been implicated as a potential biomarker in pre-diabetic and T2D conditions [22]. The higher expression of miR23a in cord blood and placenta indicates a pre-diabetic condition in the fetus due to GDM and thus can be considered a potential biomarker to diagnose offspring diabetes - a long-term effect of GDM on neonatal health.

\section{Target gene prediction, gene ontology analysis, and pathways analysis}

Genes orchestrated by these miRNAs are predicted using programs TargetScan and miRDB. A total of 348 genes, common in TargetScan and miRDB with target score > 95 (Supplementary data S1), were uploaded in STRING v 11.0. Based on the combined score given by STRING, only 93 target genes (out of 348 target genes) were found to have a combined score > 0.9. Compared with the online database OMIM (Online Mendelian Inheritance in Men) and Gene Cards, out of 93 genes, only twenty genes were found to be GDM specific (Fig. F1). MIRNA-mRNA regulatory modules (MMRM) and protein-protein interaction (PPI) networks were constructed using Cytoscape V 3.2.1. MMRM contains a total of 348 nodes and 535 edges (Fig.3A). The protein-protein interaction network contains 93 edges with 20 GDM specific target genes (Fig.3B). Respective miRNAs of these twenty genes with their relevance score are listed in Table 2. Gene Ontology and pathways enrichment analysis was performed for these genes using DAVID v 6.7 (Supplementary data S2). Carbohydrate and fatty acid metabolism, cellular response to insulin stimulus, gene silencing by miRNA, negative regulation of insulin-like growth factor, and insulin receptor signaling are major significant $(p$ value $<0.05)$ roles enriched for the target genes of these up-regulated miRNAs (Fig. 4A). Pathway analysis using DAVID resulted in an enrichment of 18 significant and rank-ordered list of pathways ( $p$ value $<0.05$ ) for predicted miRNA target genes specific to GDM (Fig. 4B). These pathways included Insulin signaling, Type II diabetes mellitus, MAPK, and JAK-STAT signaling (both are the mediator of the inflammatory pathway), chemokine signaling, ErbB signaling, and T-cell/B-cell receptor pathways, GnRH signaling, and VEGF signaling.

\section{The miRNAs target several genes involved in insulin signaling pathways and inflammation.}

A gene-regulatory network involving four significantly expressed miRNAs was constructed based on these findings, including 12 target genes and 18 pathways (Fig. 3C). An in-depth analysis revealed that miR 7, miR 9, and let 7a targets MAPK signaling via NRAS, RAF1, and MEF2C genes while miR23a regulates JAK-STAT via IL6R; both of these pathways play 
an essential role in inflammation. Mir 7 and Mir 9 regulate insulin signaling pathways and Type II diabetes mellitus by targeting IRS1 and IRS2. IRS2 is regulated by both miR 7 and miR9.

Furthermore, besides their role in inflammation and insulin signaling, these miRNAs have also been indicated to be involved in $\mathrm{GnRH}$ signaling, T-cell/B-cell receptor signaling pathways, VEGF signaling, and chemokine signaling pathway (Fig. 3C). The function of the genes related to all these pathways is listed in Table 3. It suggests that these miRNAs regulate several genes involved in inflammation, immune, and hormonal response through some unknown complex mechanism providing insights into the indirect role of these miRNAs in developing and progressing gestational diabetes mellitus.

\section{Comparison of selected target gene expressions in MB, CB, and PL of GDM vs. NGT lead to the identification of IRS1, IRS2, and RAF1 as significant target genes.}

Based on the networking and pathway enrichment analysis, six genes, namely IRS1, IRS2, RAF1, IL6R, PGC1A, and NRAS were selected for quantitative expression analysis. All these genes are primarily involved in inflammation, immune response, and insulin signaling pathway besides their role in other pathways (Fig. 7). The relative expression analysis revealed that all these genes are down-regulated in all three samples (Maternal Blood Serum $(n=15)$, Cord Blood Serum $(n=15)$, and Placenta $(n=15)$ ) of GDM mothers compared to control (NGT). In maternal blood $(n=15)$, expression of NRAS, RAF, IRS2, and IL6R was found to be significantly down-regulated (Fig. 5 A-F). Expression of all the genes was found to be down-regulated also in the case of cord blood (Fig. 5 G-L) and placenta (Fig. 5 M-R). Sample-wise comparison of the fold change ( $2^{\wedge}$-ddCt) expression of target genes reveals a higher fold change value of all six target genes in cord blood than maternal blood $(n=15)$ and placenta $(n=15)$ (Fig. 6 A-F).

Gene-wise comparison of fold change expression in each sample reveals a lower expression of IRS1 and IRS2 while comparatively higher expression of NRAS in maternal and cord serum as compared to the placenta (Fig. 6 G-I). Furthermore, micro-RNA 7 expression was highest in maternal blood while lowest in cord blood (Fig. 2B, 2C); conversely, the expression of RAF1 (Fig. 6B), IRS1 (Fig. 6D), and IRS2 (Fig. 6E) and are lowest in maternal blood while highest in cord blood. Thus it is evident that increased miRNA7 expression in maternal blood causes down-regulation of its target genes IRS1, IRS2, and RAF1 in maternal blood of GDM ( $n=15)$ mother as compared to control $(n=15)$.

\section{MIR-7 directly targets IRS, IR2, and RAF1}

A transfection assay was performed to know the inhibitory effect of miR-7 on IRS1/2 and RAF1. MicroRNA-7 mimics and inhibitors were transfected to PANC-1 cells in combination as well as alone (Fig. 7A). The group transfected only with mir-7-mimics shows significantly reduced expression of IRS1/2 and RAF1 than the control group transfected with control RNA (Fig. 7B, C). Furthermore, co-transfection of PANC-1 with miR-7-mimics and miR-7inhibitor shows comparatively higher expression of IRS1/2/RAF1 than the control and cotransfected group while the cells transfected only with miR-7-inhibitor shows the highest expression of IRS1/2/RAF1 than all other groups (Fig. 7B, C). Thus, the increased expression of IRS1/2/RAF1 in the absence of miR-7 and vice-versa confirms that miR-7 is targeting IRS1/2/RAF1.

\section{Correlation of LH/FSH and miRNAs expression}

Despite their role in insulin metabolism, miRNA7 has also been shown to regulate GnRH (Gonadotrophic Releasing Hormone) signaling pathway (Fig. 3C). MicroRNA7 is considered as prototypical endocrine miRNA and expressed at high levels in the endocrine pancreas, pituitary, and adrenal glands [25]. Further, Ahmed et al. have shown that loss of miR 7 induces hypogonadotropic hypogonadism [23]. In our study, the level of LH (Luteinizing Hormone) and FSH (Follicle Stimulating Hormone) was significantly higher 
(LH, p = 0.001; FSH, p =0.04) in GDM as compared to the NGT group (Fig. 7D; Table 1). Correlation analysis revealed a significant correlation of LH with miR 9 and miR 18a. Further, the expression of miR-7 correlates with the expression of miR-9 while miR-9 expression correlates with miR-18a expression. Thus miR-7 was found to be indirectly correlating with the LH level in GDM (Fig. 7E). Thus, the increased level of miRNA7 is somehow regulating synthesis and secretion of gonadotrophin in GDM, which is consistent with the other findings suggesting the endocrine nature of miRNA7; however, further experimentation is required to validate it.

\section{Overview of the study}

Out of all five miRNAs analyzed in three samples of GDM vs. NGT, miRNA 7 was highly expressed in the maternal blood of GDM. The higher expression of miRNAs 7 leads to down-regulation of IRS1, IRS2, and RAF1, involved in multiple pathways like insulin signaling, GnRH signaling, and inflammatory and immune response. Further, the same pattern of expression was found in cord blood, and, being circulating miRNAs, it can be thought to enter the fetal circulation via maternal blood, leading to several fetal complications (Fig.11).

\section{Discussion}

Gestational diabetes mellitus is the most common type of diabetes found in pregnancy, with increasing prevalence worldwide. It represents a metabolic syndrome associated with an altered insulin metabolism leading to increased risk of pregnancy complications and adverse infant outcomes [26-28]. Despite continuous efforts being made, the pathophysiology of the onset and progression of GDM is still a mystery. Micro-RNAs have emerged as a new player in all biological processes and pathways involved in both physiological and pathological conditions. Being secreted in body fluids by almost every cell types [29] and mediating tissue crosstalk, it has been suggested as "new hormones" [30]. Consequently, investigating circulating micro-RNAs will come up with new insight into the molecular mechanism of gestational diabetes, and thus, it may reveal both new biomarkers and the new pathogenic mechanism.

Several studies have reported expression of miRNA in different samples of GDM like maternal blood [30, 31] omental adipose tissue [32], umbilical vein endothelial cell [33], and placenta [34] Furthermore, expression of these miRNAs have been reported mainly in case of type2diabetes. However, no group has reported comparative miRNAs expression in three different samples, i.e., placental tissue $(n=15)$, cord blood serum $(n=15)$, and maternal blood serum $(n=15)$ of GDM simultaneously. In the current study, we have assessed the expression profile of five miRNAs, namely let7a, miR7, miR9, miR18a, and miR23a, in matched placental tissue $(n=15)$, cord blood serum $(n=15)$, and maternal blood serum $(n=15)$ derived from healthy pregnant women and diabetic pregnant patients () with the aim: (i) to correlate the expression of miRNA and its target gene in three samples namely maternal blood serum, cord blood serum and placenta (ii) to elucidate new pathogenic mechanism leading to onset and progression of GDM; (iii) to elucidate the role of inflammation in the pathophysiology of GDM. To achieve this, samples were collected using a standardized protocol with informed consent from the patient. Samples were then processed following all necessary procedures to evaluate the expression of miRNAs reliably. Adopting such an approach, we finally established the significant up-regulation of let 7a, miR7, miR9, miR18a, and miR23a in matched serum and tissue samples of GDM vs. NGT. The highest expression of these miRNAs 
was reported in maternal blood serum followed by the placenta, while the least expressed in cord blood serum. This gradual decrease in expression of these miRNAs from maternal blood to cord blood reinforces the idea of miRNA as hormones and mediators of tissue crosstalk which diffuses from the maternal circulation to fetal blood and forms a gradient similar to hormone (Fig 8). Although all miRNAs were up-regulated, miRNA 7 was highly expressed in all three samples. Micro RNA 7 is abundantly expressed in islets cells of the pancreas, and its overexpression in transgenic mice causes diabetes; furthermore, inhibition of miR-7 in islets cells significantly improves the insulin content and secretion [13]. It supports our findings and emphasizes the role of miR 7 in the progression of GDM. Another report further supports our result, suggesting that inhibition of miR-7 enhances adult $\beta$-cell replication in primary islets cells of mouse by targeting the mTOR signaling pathway [35]. Micro RNA 7 has also been reported as a valuable biomarker for type 2 diabetes [21]. Thus, enhanced expression of miR-7 in GDM might play a similar role in the progression of GDM and hence can be considered one of the potential biomarkers and therapeutic targets.

Apart from the role of miR-7 in diabetes, another four significantly up-regulated miRNAs, miR-9, miR-18a, let-7a, and miR-23a, have also been found to play an essential role in diabetes. Micro-RNA 9 is a negative regulator of insulin secretion from mouse beta cells [14], while an increased level of miR-18a is associated with insulin resistance and the risk of T2D Mellitus [20]. Yang et al. reported miR-23a as a promising biomarker for the early detection of pre-diabetes and T2D [22].

Pathway enrichment analysis disclosed that these miRNAs are involved in the regulation of essential pathways like MAPK signaling, JAK-STAT signaling, Insulin signaling, T2D Mellitus, ErbB signaling, and T/B-cell receptor GnRH signaling, and VEGF signaling. GDM is characterized by altered insulin and glucose metabolism, like other forms of hyperglycemia. All these miRNAs that were significantly upregulated in GDM were all associated with the insulin signaling pathway. These miRNAs, namely let 7a$5 p$, miR 7-5p, miR 9-5p, miR-18a 5p, and miR 23a-3p, regulate the insulin signaling pathway by targeting genes NRAS RAF1, IRS1, IRS2, and PPARGC1A, respectively. The quantitative expressions revealed the down-expression of all these target genes in GDM mothers as compared to control. Up-regulation of these miRNAs resulted in the down-regulation of NRAS, RAF1, IRS1, IRS2, and PPARGC1A leading to aberrant insulin signaling causing insulin resistance and eventually leading to diabetes. Transfection assays further confirm the inhibitory effect of miRNA 7 on the expression of IRS1/2/RAF1. MicroRNA-7-mimics has been found to down-regulate the IRS1/2/RAF1 expression at mRNA level, while in the presence of miR-7-inhibitor, the expression of IRS1/2/RAF1 goes up. Micro-RNA-gene regulatory network revealed that miR-7 regulates insulin signaling pathway and T2D Mellitus by targeting genes like IRS1 and IRS2. These IRS1 and IRS2 are adaptor proteins that regulate insulin-like growth factor-I (IGF-I)/insulin signaling and are involved in variety of biological processes, including carbohydrate metabolism, proliferation, differentiation, and apoptosis [36, 37]. At the same time, miR-23a regulates the IRS1:IRS2 ratio and influences insulin signaling by targeting PPARGC1A [38]. Furthermore, miR-7 and miR-9 have been reported as negative factors of insulin secretion [14, 21]. On the other hand, NRAS (target gene of let-7a) was also found to regulate the insulin signaling pathway, is critical for cell growth, and has been linked to cancer, obesity, and diabetes [39-41]. Hence, miRNA 7, along with miR-9 and let-7a, alters the insulin 
signaling pathway leading to altered insulin metabolism. All these findings indicate the critical role of these miRNAs in the development of gestational diabetes mellitus.

Low-grade chronic inflammation has long been known to play an essential role in many diseases, including cancer and diabetes [42]. Several groups have reported the role of these miRNAs in cancer and inflammation [35, 43-46], suggesting a similar role of these miRNAs in the progression of GDM. Pathway enrichment analysis and miRNA-gene regulatory network identify altered MAP Kinase and JAK-STAT signaling-both of which are the essential mediator in the development and progression of inflammation [42]. MiR-7 and let-7a regulated MAP Kinase signaling via targeting gene RAF1 and NRAS (Fig. 3C), respectively, while miR-23a regulated JAK-STAT signaling via targeting IL6R. Our finding is supported by reports where chronic, low-grade inflammation termed "metal inflammation" has already been implicated to play a crucial role in the development of type2diabetes as well as GDM $[47,48]$. Hence, miR-7 and other micro-RNA will be altering inflammatory pathways leading to chronic low-grade inflammation (metainflammation) and thus contributing to the progression of GDM.

Out of five miRNAs that were up-regulated in GDM, three miRNAs, namely let-7a, miR-23a, and miR-7, regulate pathways related to immune response (T-cell/B-cell receptor signaling, NK cell-mediated cytotoxicity, and cytokine-cytokine receptor interaction). These are the same sets of miRNAs that were earlier found to be involved in altered inflammation. Inflammation and immune response are two sides of the same coin, so a slight variation in already compromised maternal immune response (due to allogeneic fetus) will elicit the inflammation. It further adds up complexity and confirms a correlation between inflammation and GDM, reinforcing a potential view of these miRNAs as an indicator of aggressive diabetic phenotype.

Despite their role in insulin signaling, inflammation, and immune response, these miRNAs, particularly miRNA 7-5P and let-7a, have also been found to regulate the GnRH signaling pathway (Fig. 3C). MicroRNA 7 is a prototypical endocrine miRNA $[25,49]$ and may act like an endocrine hormone regulating the synthesis and secretion of gonadotrophin-releasing hormone (GnRH). The role of GnRH in GDM development has not been reported anywhere; however, United States Food and Drug Administration (FDA) has warned about the increased risk of diabetes and cardiovascular disease due to GnRH agonist treatment in cancer [50]. It provides insight into the role of GnRH in the development of GDM. Hence, miRNA 7 is also acting as a hormone and altering GnRH signaling, consequently leading to GDM. Overall such results pointed out the potential role of miR-7 in GDM development and progression via regulating multiple pathways (Fig. 8) and thus can be considered a new biomarker of GDM. However, this study has one potential limit of being a small number of sample sizes but use of specific and stringent procedure for blood collection, serum isolation cDNA library preparation and miRNAs analysis provided sufficient precision to attain statistically significant results. Therefore, although more studies are required to strengthen these results, the quantification of circulating levels of these sets of miRNAs may help predict diabetic outcome and/or severity and thus help provide personalized therapy in GDM.

\section{Conclusion}


In conclusion, the current study demonstrated that the elevated level of miRNA7 might be associated with the progression of GDM by altering the multiple pathways like insulin, $\mathrm{GnRH}$, and inflammatory signaling pathways via targeting IRS1, IRS2, and RAF1, suggesting a new therapeutic target for GDM. Micro-RNA 7 is involved in insulin metabolism, inflammation, as well as hormone response and thus, may also provide new understanding of molecular mechanisms that underlie GDM. Finally, we suggest miRNA-7 may be used as a diagnostics marker and therapeutic targets both. However, further studies are required to confirm the use of these miRNA7 as a biomarker and their role in GDM development and progression.

\section{Declarations}

\section{Ethics statement}

This study was carried out following the required local ethical recommendations (Banaras Hindu University). All procedures followed were following the ethical standards of the responsible committee on human experimentation. Informed consent was obtained from all patients for being included in the study.

\section{Funding}

This work was supported by the Indian Council of Medical Research (ICMR).

\section{Acknowledgments}

This work was supported by the Indian Council of Medical Research.

\section{Conflict of interest}

The authors have no conflicts of interest.

\section{References}

1. Association AD (2004) Gestational Diabetes Mellitus. Diabetes Care 27(suppl 1):s88-s90. https://doi.org/10.2337/diacare.27.2007.S88

2. Landon MB, Carpenter MW, Wapner RJ, et al (2009) A Multicenter, Randomized Trial of Treatment for Mild Gestational Diabetes. The New England Journal of Medicine 10

3. Dabelea D, Hanson RL, Lindsay RS, et al (2000) Intrauterine exposure to diabetes conveys risks for type 2 diabetes and obesity: a study of discordant sibships. Diabetes 49(12):2208-2211. https://doi.org/10.2337/diabetes.49.12.2208 
4. Poirier C, Desgagné V, Guérin R, Bouchard L (2017) MicroRNAs in Pregnancy and Gestational Diabetes Mellitus: Emerging Role in Maternal Metabolic Regulation. Curr Diab Rep 17(5):35. https://doi.org/10.1007/s11892-017-0856-5

5. Guarino E, Delli Poggi C, Grieco GE, et al (2018) Circulating MicroRNAs as Biomarkers of Gestational Diabetes Mellitus: Updates and Perspectives. International Journal of Endocrinology 2018:111. https://doi.org/10.1155/2018/6380463

6. Liu L, Zhang X, Rong C, et al (2014) Distinct DNA Methylomes of Human Placentas Between PreEclampsia and Gestational Diabetes Mellitus. Cell Physiol Biochem 34(6):1877-1889. https://doi.org/10.1159/000366386

7. Özcan S (2014) Minireview: MicroRNA Function in Pancreatic $\beta$ Cells. Molecular Endocrinology 28(12):1922-1933. https://doi.org/10.1210/me.2014-1306

8. Needhamsen M, White RB, Giles KM, Dunlop SA, Thomas MG (2014) Regulation of Human PAX6 Expression by miR-7. Evol Bioinform Online 10:EBO.S13739. https://doi.org/10.4137/EBO.S13739

9. Meza-Sosa KF, Pérez-García El, Camacho-Concha N, López-Gutiérrez O, Pedraza-Alva G, PérezMartínez L (2014) MiR-7 Promotes Epithelial Cell Transformation by Targeting the Tumor Suppressor KLF4. PLoS ONE 9(9):e103987. https://doi.org/10.1371/journal.pone.0103987

10. Davalos A, Goedeke L, Smibert P, et al (2011) miR-33a/b contribute to the regulation of fatty acid metabolism and insulin signaling. Proceedings of the National Academy of Sciences 108(22):92329237. https://doi.org/10.1073/pnas.1102281108

11. Feng $Y$, Qu X, Chen $Y$, et al (2020) MicroRNA-33a-5p sponges to inhibit pancreatic $\beta$-cell function in gestational diabetes mellitus LncRNA DANCR. Reprod Biol Endocrinol 18(1):61. https://doi.org/10.1186/s12958-020-00618-8

12. Wang T, Zhu H, Yang S, Fei X (2019) Let-7a-5p may participate in the pathogenesis of diabetic nephropathy through targeting HMGA2. Mol Med Report. https://doi.org/10.3892/mmr.2019.10057

13. Xu H, Guo S, Li W, Yu P (2015) The circular RNA Cdr1as, via miR-7 and its targets, regulates insulin transcription and secretion in islet cells. Sci Rep 5(1):12453. https://doi.org/10.1038/srep12453

14. Hu D, Wang $Y$, Zhang H, Kong D (2018) Identification of miR-9 as a negative factor of insulin secretion from beta cells. J Physiol Biochem 74(2):291-299. https://doi.org/10.1007/s13105-018-0615-3

15. Bartel DP (2009) MicroRNAs: Target Recognition and Regulatory Functions. Cell 136(2):215-233. https://doi.org/10.1016/j.cell.2009.01.002

16. Wong N, Wang X (2015) miRDB: an online resource for microRNA target prediction and functional annotations. Nucleic Acids Research 43(D1):D146-D152. https://doi.org/10.1093/nar/gku1104 
17. Szklarczyk D, Gable AL, Lyon D, et al (2019) STRING v11: protein-protein association networks with increased coverage, supporting functional discovery in genome-wide experimental datasets. Nucleic Acids Research 47(D1):D607-D613. https://doi.org/10.1093/nar/gky1131

18. Kohl M, Wiese S, Warscheid B (2011) Cytoscape: Software for Visualization and Analysis of Biological Networks. In: Hamacher M, Eisenacher M, Stephan C (eds) Data Mining in Proteomics. Humana Press, Totowa, NJ, pp 291-303

19. Huang DW, Sherman BT, Lempicki RA (2009) Systematic and integrative analysis of large gene lists using DAVID bioinformatics resources. Nat Protoc 4(1):44-57. https://doi.org/10.1038/nprot.2008.211

20. Wang S-S, Li Y-Q, Liang Y-Z, et al (2017) Expression of miR-18a and miR-34c in circulating monocytes associated with vulnerability to type 2 diabetes mellitus and insulin resistance. J Cell Mol Med 21(12):3372-3380. https://doi.org/10.1111/jcmm.13240

21. Wan S, Wang J, Wang J, et al (2017) Increased serum miR-7 is a promising biomarker for type 2 diabetes mellitus and its microvascular complications. Diabetes Research and Clinical Practice 130:171179. https://doi.org/10.1016/j.diabres.2017.06.005

22. Yang Z, Chen H, Si H, et al (2014) Serum miR-23a, a potential biomarker for diagnosis of prediabetes and type 2 diabetes. Acta Diabetol 51(5):823-831. https://doi.org/10.1007/s00592-014-0617-8

23. Ahmed K, LaPierre MP, Gasser E, et al (2017) Loss of microRNA-7a2 induces hypogonadotropic hypogonadism and infertility. Journal of Clinical Investigation 127(3):1061-1074.

https://doi.org/10.1172/JCI90031

24. Peng C, Wang Y-L (2018) Editorial: MicroRNAs as New Players in Endocrinology. Front Endocrinol 9:459. https://doi.org/10.3389/fendo.2018.00459

25. Latreille M, Hausser J, Stützer I, et al (2014) MicroRNA-7a regulates pancreatic $\beta$ cell function. J Clin Invest 124(6):2722-2735. https://doi.org/10.1172/JCI73066

26. Harreiter J, Dovjak G, Kautzky-Willer A (2014) Gestational Diabetes Mellitus and Cardiovascular Risk after Pregnancy. Womens Health (Lond Engl) 10(1):91-108. https://doi.org/10.2217/WHE.13.69

27. Fraser A, Lawlor DA (2014) Long-Term Health Outcomes in Offspring Born to Women with Diabetes in Pregnancy. Curr Diab Rep 14(5):489. https://doi.org/10.1007/s11892-014-0489-x

28. Ludwig N, Leidinger P, Becker K, et al (2016) Distribution of miRNA expression across human tissues. Nucleic Acids Res 44(8):3865-3877. https://doi.org/10.1093/nar/gkw116

29. Thomou T, Mori MA, Dreyfuss JM, et al (2017) Adipose-derived circulating miRNAs regulate gene expression in other tissues. Nature 542(7642):450-455. https://doi.org/10.1038/nature21365 
30. Sebastiani G, Guarino E, Grieco GE, et al (2017) Circulating microRNA (miRNA) Expression Profiling in Plasma of Patients with Gestational Diabetes Mellitus Reveals Upregulation of miRNA miR330-3p. Front Endocrinol 8:345. https://doi.org/10.3389/fendo.2017.00345

31. Zhu Y, Tian F, Li H, Zhou Y, Lu J, Ge Q (2015) Profiling maternal plasma microRNA expression in early pregnancy to predict gestational diabetes mellitus. International Journal of Gynecology \& Obstetrics 130(1):49-53. https://doi.org/10.1016/j.ijgo.2015.01.010

32. Shi Z, Zhao C, Guo X, et al (2014) Differential Expression of MicroRNAs in Omental Adipose Tissue From Gestational Diabetes Mellitus Subjects Reveals miR-222 as a Regulator of ERa Expression in Estrogen-Induced Insulin Resistance. Endocrinology 155(5):1982-1990. https://doi.org/10.1210/en.2013-2046

33. Tryggestad JB, Vishwanath A, Jiang S, et al (2016) Influence of gestational diabetes mellitus on human umbilical vein endothelial cell miRNA. Clinical Science 130(21):1955-1967. https://doi.org/10.1042/CS20160305

34. Ding R, Guo F, Zhang Y, et al (2018) Integrated Transcriptome Sequencing Analysis Reveals Role of miR-138-5p/ TBL1X in Placenta from Gestational Diabetes Mellitus. Cell Physiol Biochem 51(2):630646. https://doi.org/10.1159/000495319

35. Wang Y, Liu J, Liu C, Naji A, Stoffers DA (2013) MicroRNA-7 Regulates the mTOR Pathway and Proliferation in Adult Pancreatic -Cells. Diabetes 62(3):887-895. https://doi.org/10.2337/db12-0451

36. Sorokin AV, Chen J (2013) MEMO1, a new IRS1-interacting protein, induces epithelialmesenchymal transition in mammary epithelial cells. Oncogene 32(26):3130-3138. https://doi.org/10.1038/onc.2012.327

37. Besse-Patin A, Jeromson S, Levesque-Damphousse P, Secco B, Laplante M, Estall JL (2019) PGC1A regulates the IRS1:IRS2 ratio during fasting to influence hepatic metabolism downstream of insulin. Proc Natl Acad Sci USA 116(10):4285-4290. https://doi.org/10.1073/pnas.1815150116

38. Germann UA, Furey BF, Markland W, et al (2017) Targeting the MAPK Signaling Pathway in Cancer: Promising Preclinical Activity with the Novel Selective ERK1/2 Inhibitor BVD-523 (Ulixertinib). Mol Cancer Ther 16(11):2351-2363. https://doi.org/10.1158/1535-7163.MCT-17-0456

39. Bost F, Aouadi M, Caron L, Binétruy $B$ (2005) The role of MAPKs in adipocyte differentiation and obesity. Biochimie 87(1):51-56. https://doi.org/10.1016/j.biochi.2004.10.018

40. Zhang W, Thompson BJ, Hietakangas V, Cohen SM (2011) MAPK/ERK Signaling Regulates Insulin Sensitivity to Control Glucose Metabolism in Drosophila. PLoS Genet 7(12):e1002429. https://doi.org/10.1371/journal.pgen.1002429 
41. Coussens LM, Werb Z (2002) Inflammation and cancer. Nature 420(6917):860-867. https://doi.org/10.1038/nature01322

42. Duncan BB, Schmidt MI, Pankow JS, et al (2003) Low-Grade Systemic Inflammation and the Development of Type 2 Diabetes: The Atherosclerosis Risk in Communities Study. Diabetes 52(7):17991805. https://doi.org/10.2337/diabetes.52.7.1799

43. Chen X, Yang F, Zhang T, et al (2019) MiR-9 promotes tumorigenesis and angiogenesis and is activated by MYC and OCT4 in human glioma. J Exp Clin Cancer Res 38(1):99.

https://doi.org/10.1186/s13046-019-1078-2

44. Mai S, Xiao R, Shi L, et al (2019) MicroRNA-18a promotes cancer progression through SMG1 suppression and mTOR pathway activation in nasopharyngeal carcinoma. Cell Death Dis 10(11):819. https://doi.org/10.1038/s41419-019-2060-9

45. Deng $\mathrm{YH}$, Deng ZH, Hao H, et al (2018) MicroRNA-23a promotes colorectal cancer cell survival by targeting PDK4. Experimental Cell Research 373(1-2):171-179.

https://doi.org/10.1016/j.yexcr.2018.10.010

46. Chirshev E, Oberg KC, loffe YJ, Unternaehrer JJ (2019) Let-7 as biomarker, prognostic indicator, and therapy for precision medicine in cancer. Clin Transl Med 8. https://doi.org/10.1186/s40169-0190240-y

47. Chen L, Deng $\mathrm{H}$, Cui $\mathrm{H}$, et al (2018) Inflammatory responses and inflammation-associated diseases in organs. Oncotarget 9(6):7204-7218. https://doi.org/10.18632/oncotarget.23208

48. Pantham P, Aye ILMH, Powell TL (2015) Inflammation in maternal obesity and gestational diabetes mellitus. Placenta 36(7):709-715. https://doi.org/10.1016/j.placenta.2015.04.006

49. Correa-Medina M, Bravo-Egana V, Rosero S, et al (2009) MicroRNA miR-7 is preferentially expressed in endocrine cells of the developing and adult human pancreas. Gene Expression Patterns 9(4):193-199. https://doi.org/10.1016/j.gep.2008.12.003

50. Saylor PJ, Keating NL, Freedland SJ, Smith MR (2011) Gonadotropin releasing hormone (GnRH) agonists and the risks of diabetes and cardiovascular disease in men with prostate cancer. Drugs 71(3):255-261. https://doi.org/10.2165/11588930-000000000-00000

\section{Tables}

Table 1 Maternal clinical characteristics of the study population. 
Clinical Parameter

Value

Maternal Characteristics

Age (years)

$0.0002011^{*}$

BMI $\left(\mathrm{Kg} / \mathrm{m}^{2}\right)$

$0.0001963^{*}$

Pregnancy duration (wk) $0.0006485^{*}$

$\mathrm{LH}(\mathrm{m} \mathrm{Ul} / \mathrm{ml})$

$0.0009268^{*}$

$\mathrm{FSH}(\mathrm{m} \mathrm{Ul} / \mathrm{ml})$

$0.0333753^{*}$

HbA1c (\%)

$0.0149365^{\star}$
NGT pregnant patients $(n=15)$

GDM patients ( $n=15)$

p
$25.2 \pm 2.8$

$21.5 \pm 2.0$

$38.7 \pm 1.0$

$3.82 \pm 1.3$

$5.43 \pm 2.0$

$4.8 \pm 0.6$
$35.4 \pm 5.0$

$27.5 \pm 4.1$

$36.2 \pm 1.4$

$8.27 \pm 3.7$

$11.64 \pm 6.1$

$6.5 \pm 1.9$

LH, Luteinizing hormone; FSH, Follicle Stimulating Hormone; HbA1c; Glycosylated hemoglobin; Data are reported as mean $\pm S D$. ${ }^{*}$ Significant value

Table 2 GDM specific genes regulated by miRNA with a relevance score. 


\begin{tabular}{|c|c|c|}
\hline miR ID & Gene & Relevance Score \\
\hline \multirow{6}{*}{ Let-7a } & IGF1R & 39.96 \\
\hline & HMGA2 & 13.21 \\
\hline & ADRB2 & 10.51 \\
\hline & NRAS & 10.19 \\
\hline & COL3A1 & 2.7 \\
\hline & COIL & 0.57 \\
\hline \multirow{4}{*}{ miR7 } & IRS1 & 71.35 \\
\hline & IRS2 & 52.22 \\
\hline & RAF1 & 4.4 \\
\hline & RB1 & 3.42 \\
\hline \multirow{3}{*}{ miR9 } & FBN1 & 16.04 \\
\hline & MEF2C & 2.8 \\
\hline & KCNJ2 & 1.23 \\
\hline miR18a & TNFAIP3 & 2.64 \\
\hline \multirow{6}{*}{ miR23a } & PPARGC1A & 19.68 \\
\hline & PTEN & 14.13 \\
\hline & IL6R & 8.74 \\
\hline & MET & 7.1 \\
\hline & STAT5B & 3.61 \\
\hline & PTGER4 & 2.93 \\
\hline
\end{tabular}

Table 3 List of important target genes related to inflammation and insulin signaling. 


\begin{tabular}{|c|c|c|c|}
\hline $\begin{array}{l}\text { Official } \\
\text { Symbol }\end{array}$ & $\begin{array}{l}\text { Official full } \\
\text { name }\end{array}$ & $\begin{array}{l}\text { Sequence accession } \\
\text { ID }\end{array}$ & Function \\
\hline IRS1 & $\begin{array}{l}\text { Insulin receptor } \\
\text { substrate } 1\end{array}$ & NM_005544 & $\begin{array}{l}\text { Mediate the control of various cellular } \\
\text { processes by insulin. When } \\
\text { phosphorylated by the insulin receptor } \\
\text { binds specifically to various cellular } \\
\text { proteins containing SH2 domains such } \\
\text { as phosphatidylinositol 3-kinase p85 } \\
\text { subunit or GRB2. (18) }\end{array}$ \\
\hline IRS2 & $\begin{array}{l}\text { Insulin receptor } \\
\text { substrate } 2\end{array}$ & NM_003749 & $\begin{array}{l}\text { mediate the control of various cellular } \\
\text { processes by insulin. (19) }\end{array}$ \\
\hline MEF2C & $\begin{array}{l}\text { Myocyte-specific } \\
\text { enhancer factor } \\
2 \mathrm{C}\end{array}$ & NM_001193348 & $\begin{array}{l}\text { Transcription activator which plays a } \\
\text { role in inflammation. }(20)\end{array}$ \\
\hline PPARGC1A & $\begin{array}{l}\text { Peroxisome } \\
\text { proliferator- } \\
\text { activated } \\
\text { receptor gamma } \\
\text { coactivator 1- } \\
\text { alpha }\end{array}$ & NM_001330751 & $\begin{array}{l}\text { PGC1-alpha activates transcription in } \\
\text { cooperation with Mef2 proteins. PGC- } \\
\text { 1alpha integrates insulin signaling, } \\
\text { mitochondrial regulation, and } \\
\text { bioenergetic function in skeletal muscle. } \\
\text { (21) }\end{array}$ \\
\hline NRAS & $\begin{array}{l}\text { RAS Proto-onco } \\
\text { gene }\end{array}$ & NM_002524 & $\begin{array}{l}\text { Involved in inflammation, cell growth, } \\
\text { and differentiation via the MAPK } \\
\text { signaling pathway }(22,23) \text {. }\end{array}$ \\
\hline RAF1 & $\begin{array}{l}\text { RAF proto- } \\
\text { oncogene } \\
\text { serine/threonine- } \\
\text { protein kinase }\end{array}$ & NM_001354695 & $\begin{array}{l}\text { Activates the MAPK pathway along with } \\
\text { RAS and thus is involved in } \\
\text { inflammation (24). }\end{array}$ \\
\hline RB1 & $\begin{array}{l}\text { Retinoblastoma- } \\
\text { associated } \\
\text { protein }\end{array}$ & NM_000321 & $\begin{array}{l}\text { Plays a dual role in cell proliferation and } \\
\text { apoptosis }(25) \text {. }\end{array}$ \\
\hline IGF1R & $\begin{array}{l}\text { Insulin-like } \\
\text { growth factor } 1 \\
\text { receptor }\end{array}$ & NM_001291858 & $\begin{array}{l}\text { Mediates apoptosis-inhibiting signals, } \\
\text { and enhances cell metabolism and } \\
\text { protein synthesis via downstream } \\
\text { mechanistic target of rapamycin } \\
\text { (mTOR) kinase signaling, activates the } \\
\text { PI3K/AKT signaling pathway (26). }\end{array}$ \\
\hline IL6R & $\begin{array}{l}\text { Interleukin-6 } \\
\text { receptor }\end{array}$ & NM_181359 & $\begin{array}{l}\text { Leads to activation of JAK/STAT, ERK } \\
\text { andPI3K signal transduction pathways } \\
(28) \text {. }\end{array}$ \\
\hline
\end{tabular}


Figures
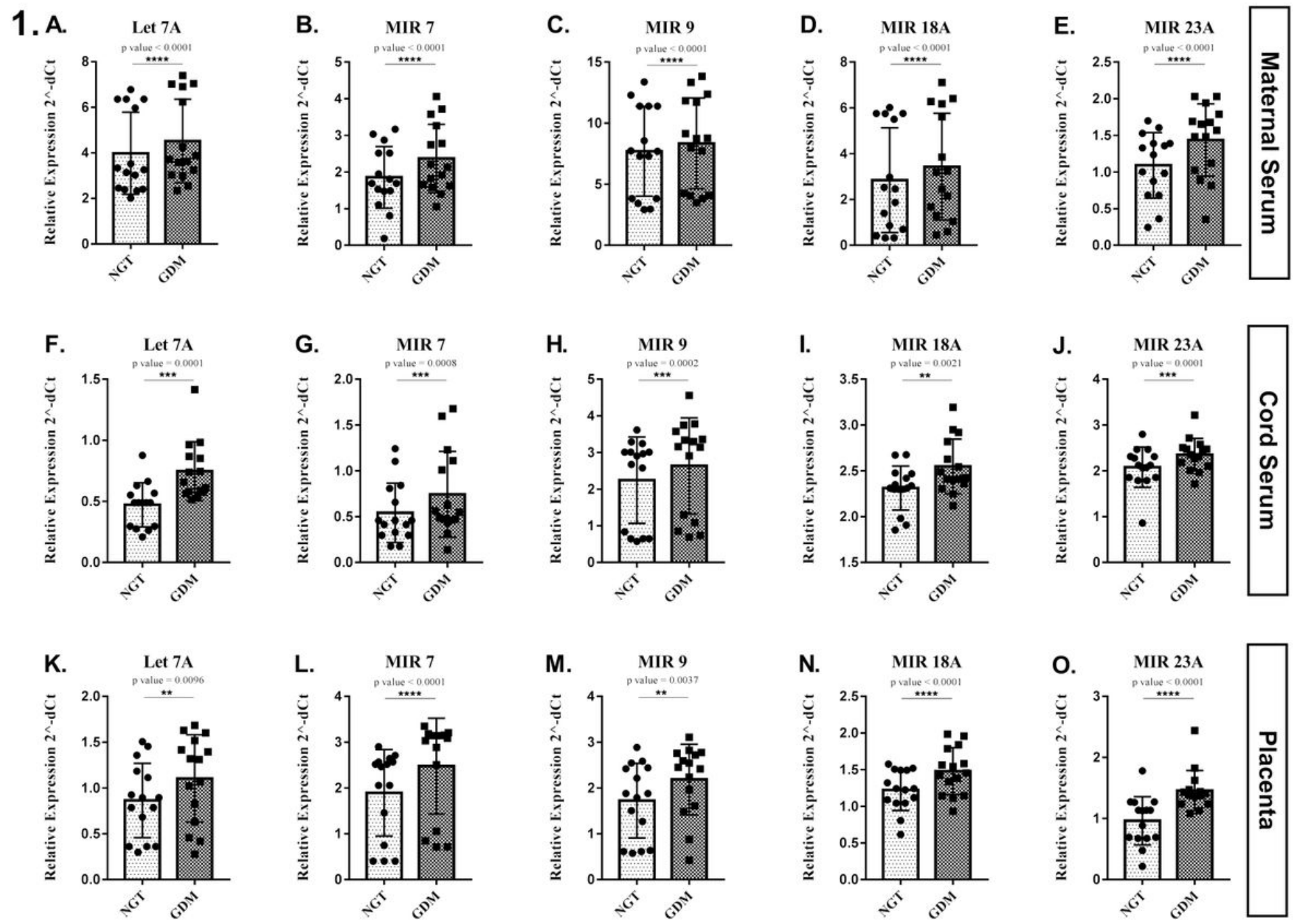

Figure 1

Figure legend not available with this version. 
2. A. Let 7A
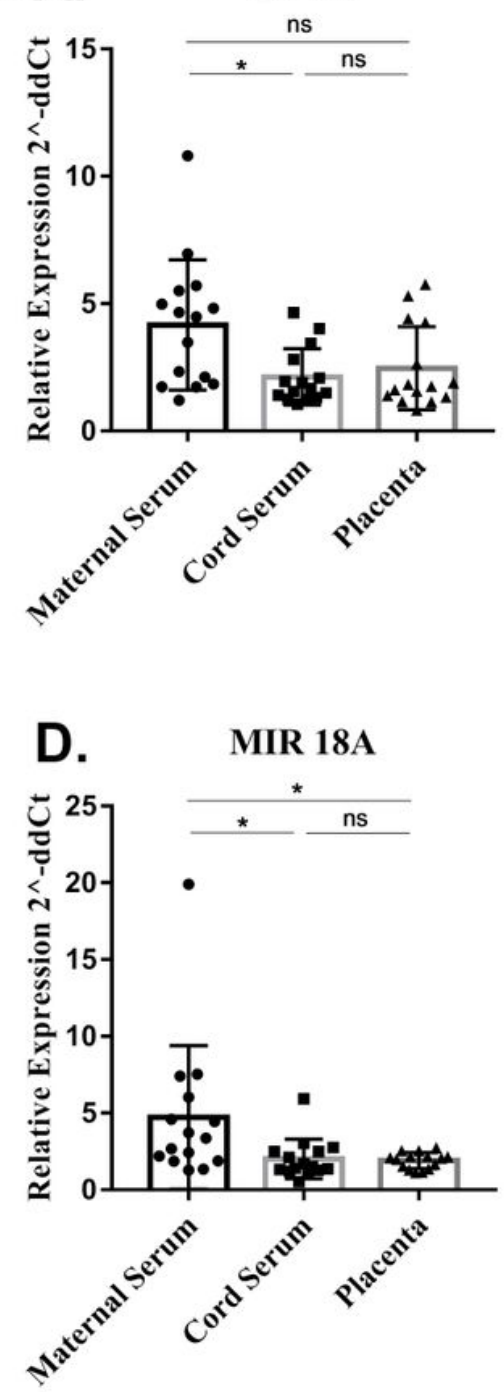
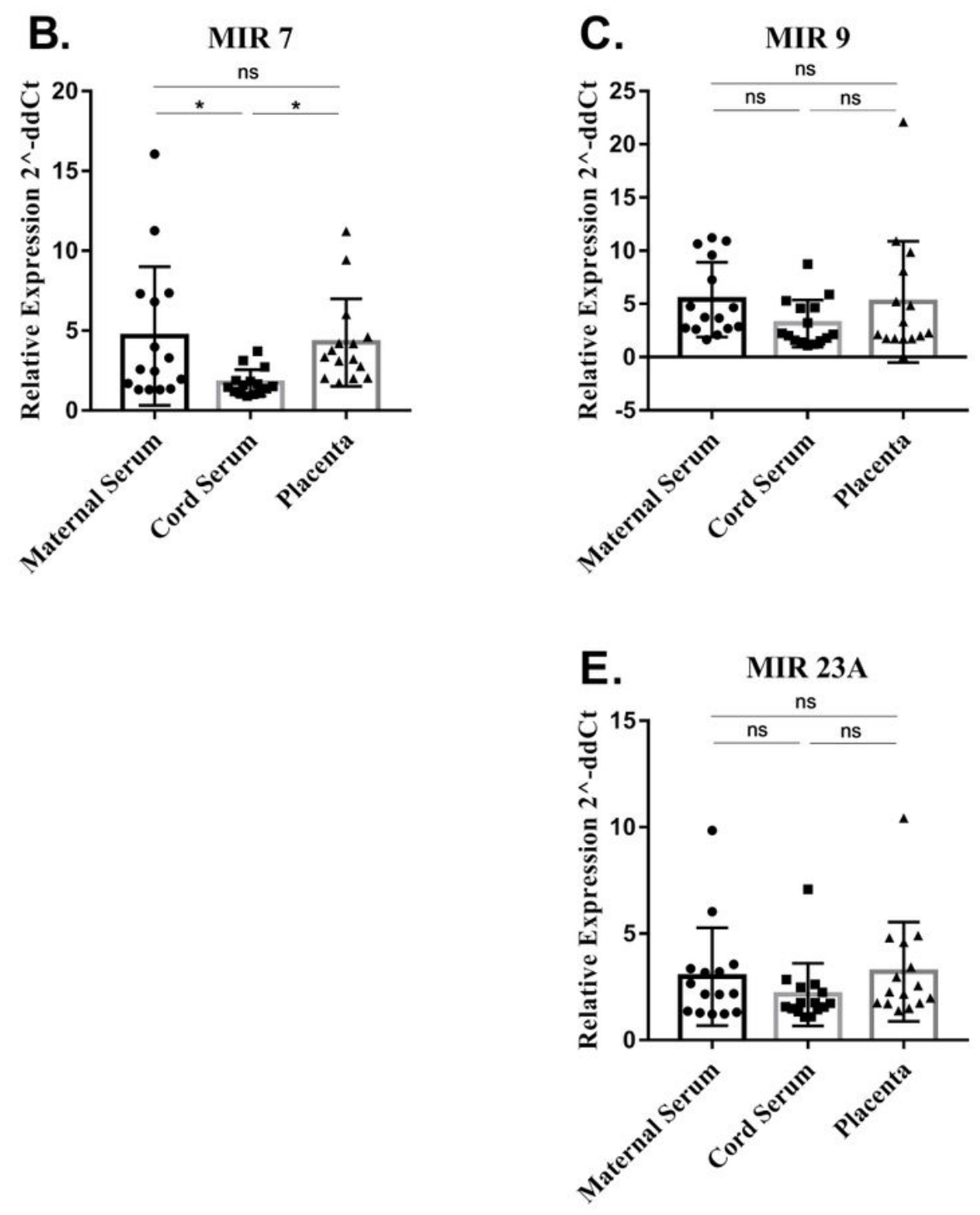

Figure 2

Figure legend not available with this version. 


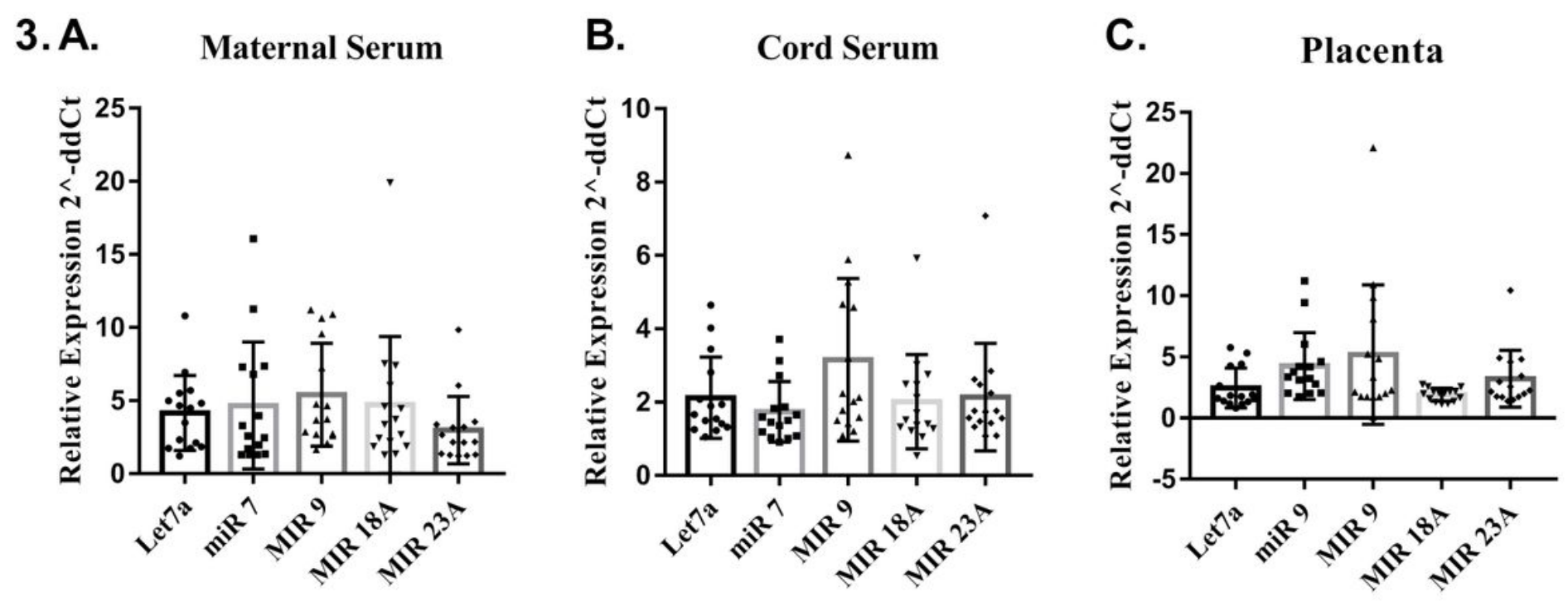

Figure 3

Figure legend not available with this version.

4.

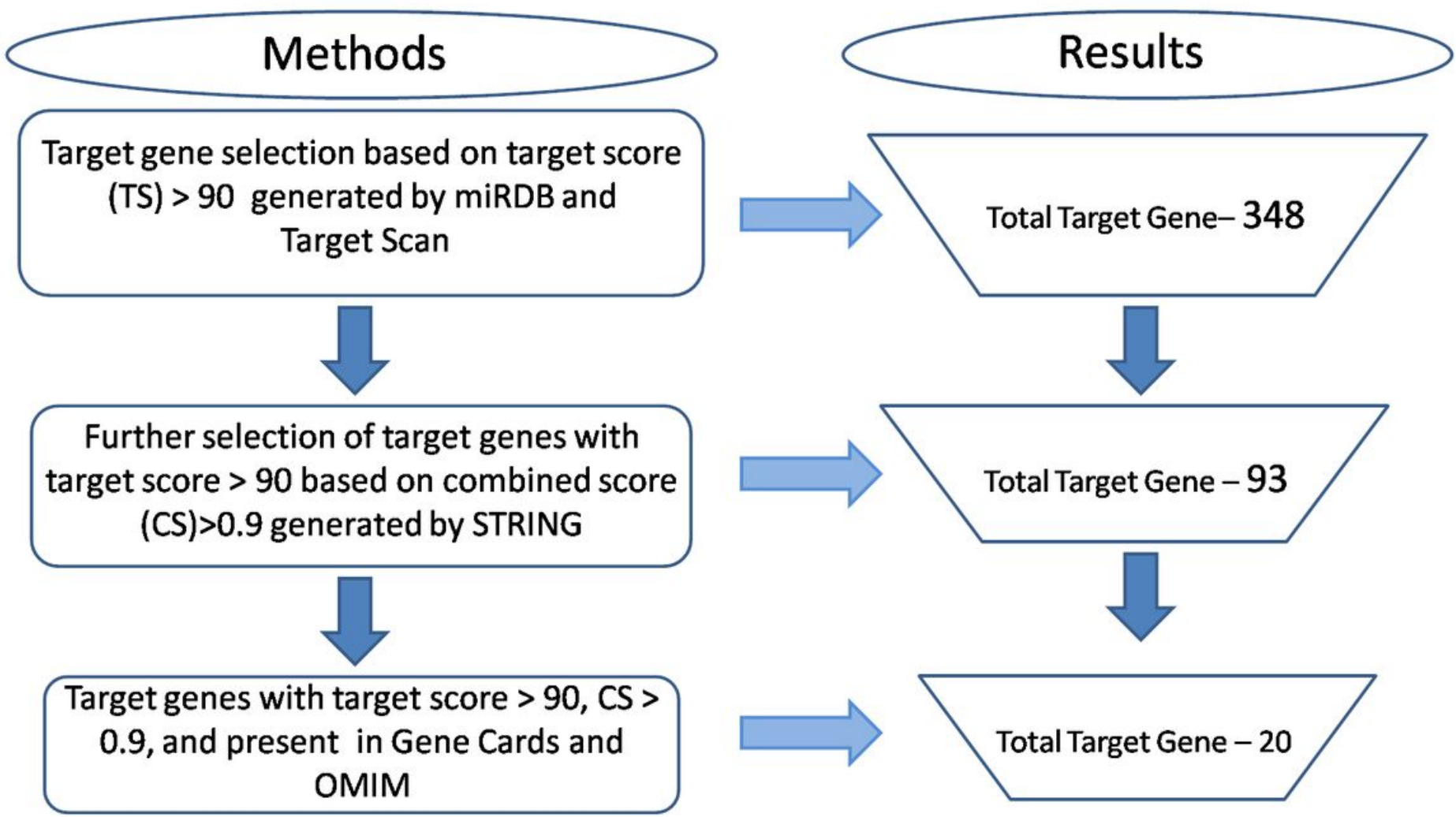

Figure 4

Figure legend not available with this version. 

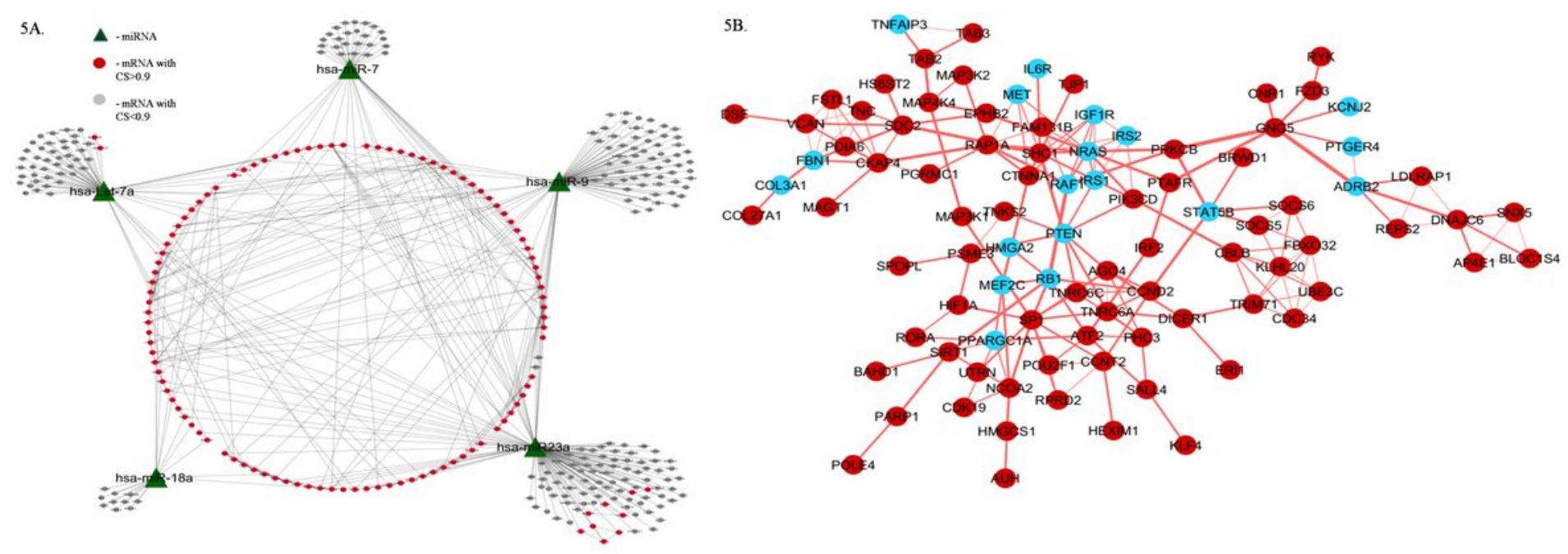

Figure 5

Figure legend not available with this version.

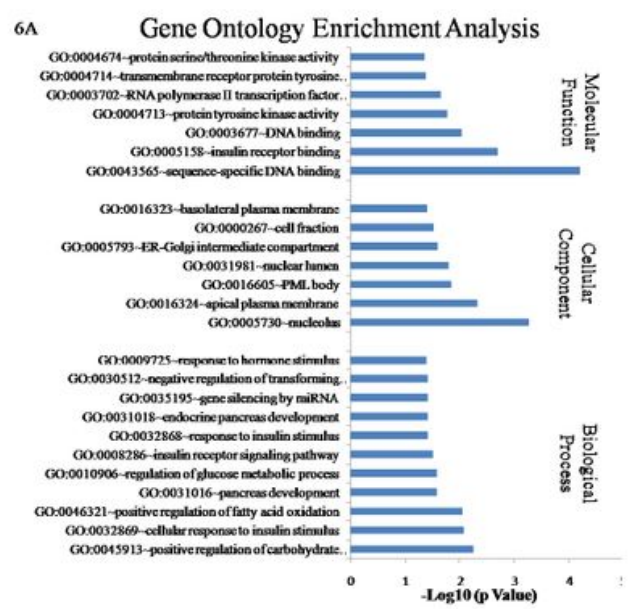

$6 \mathrm{~B}$.

KEGG Pathway Enrichment Analysis

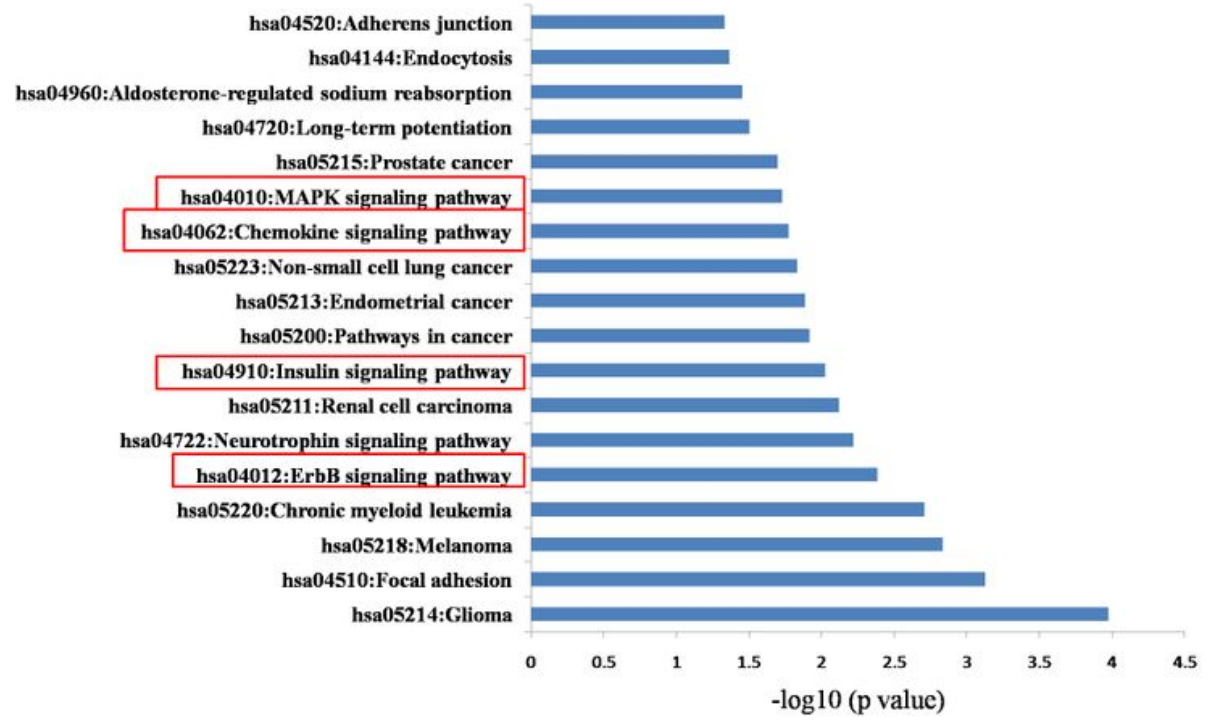

\section{Figure 6}

Figure legend not available with this version. 


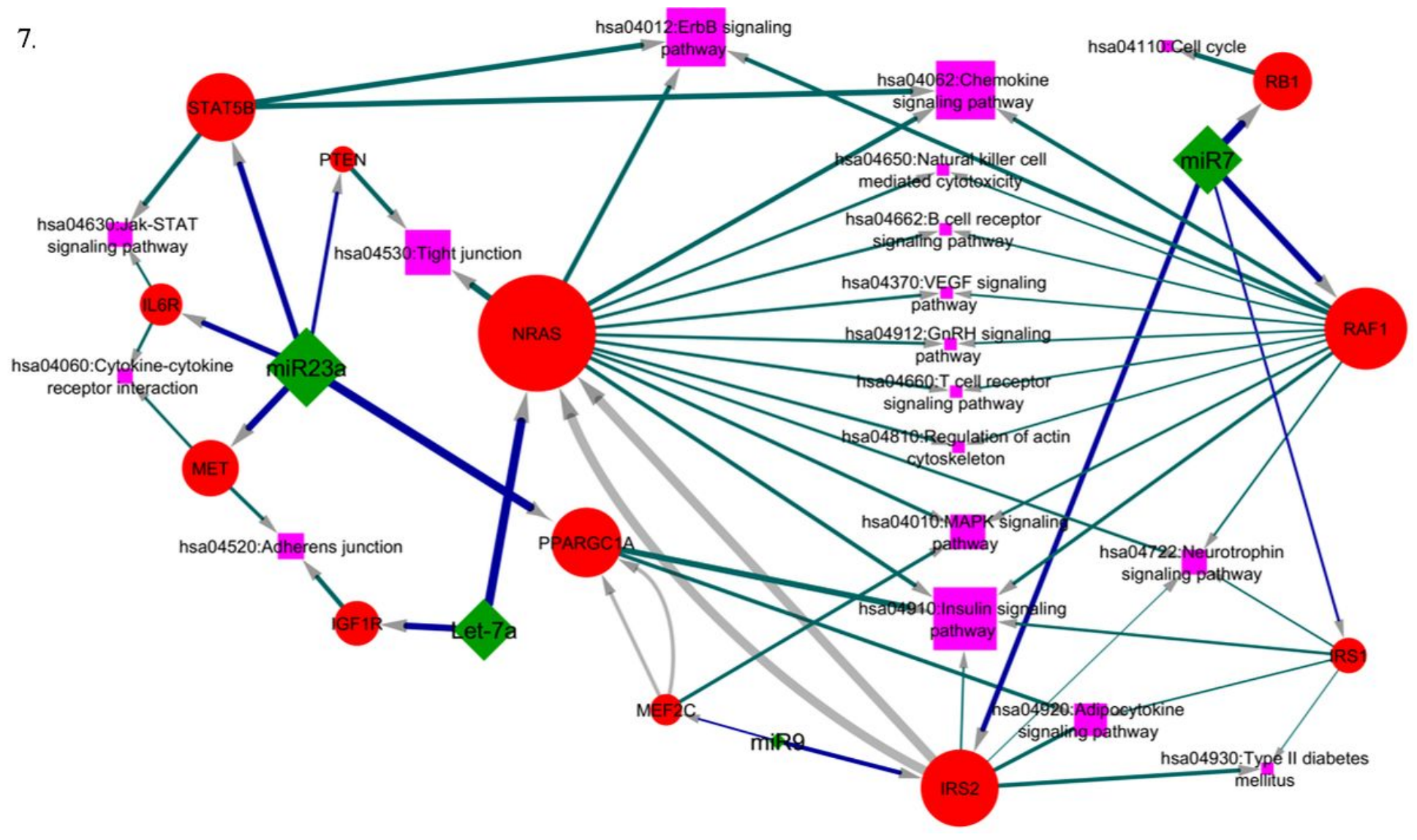

Figure 7

Figure legend not available with this version. 
8. A.

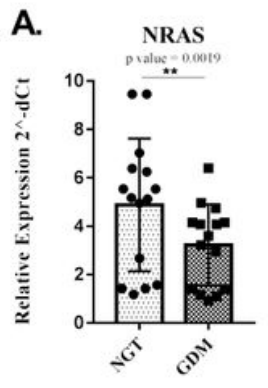

G.

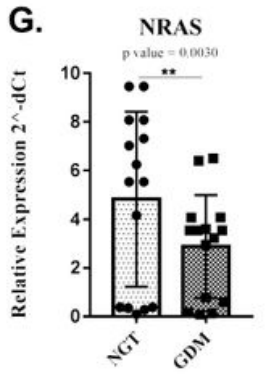

M.

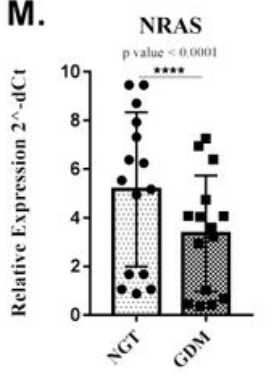

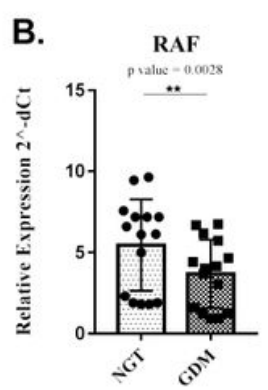
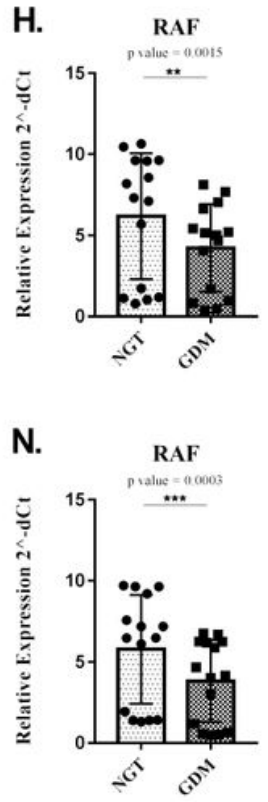
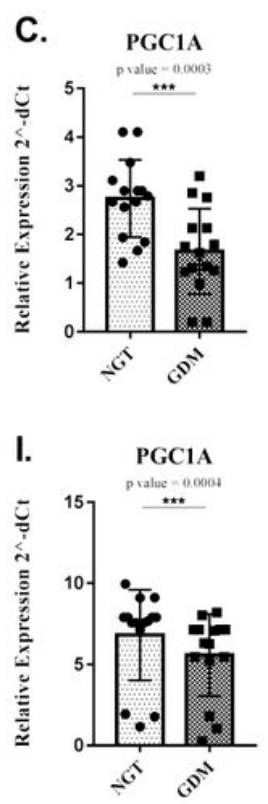

O. PGC1A

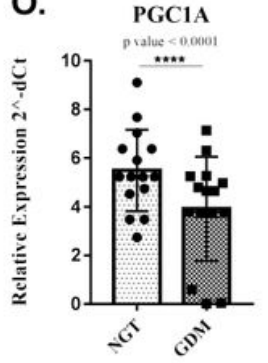

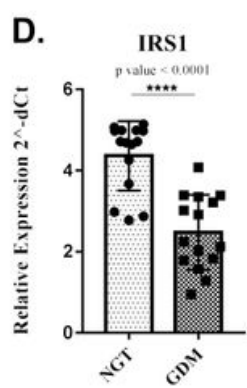
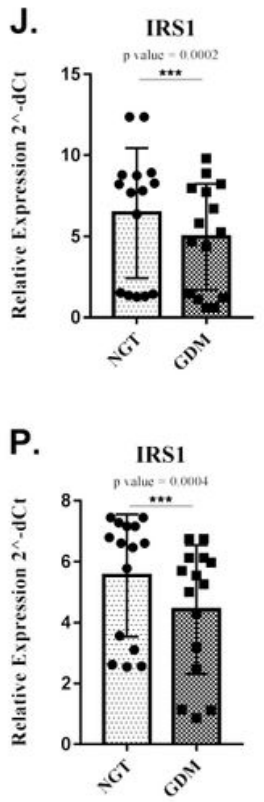
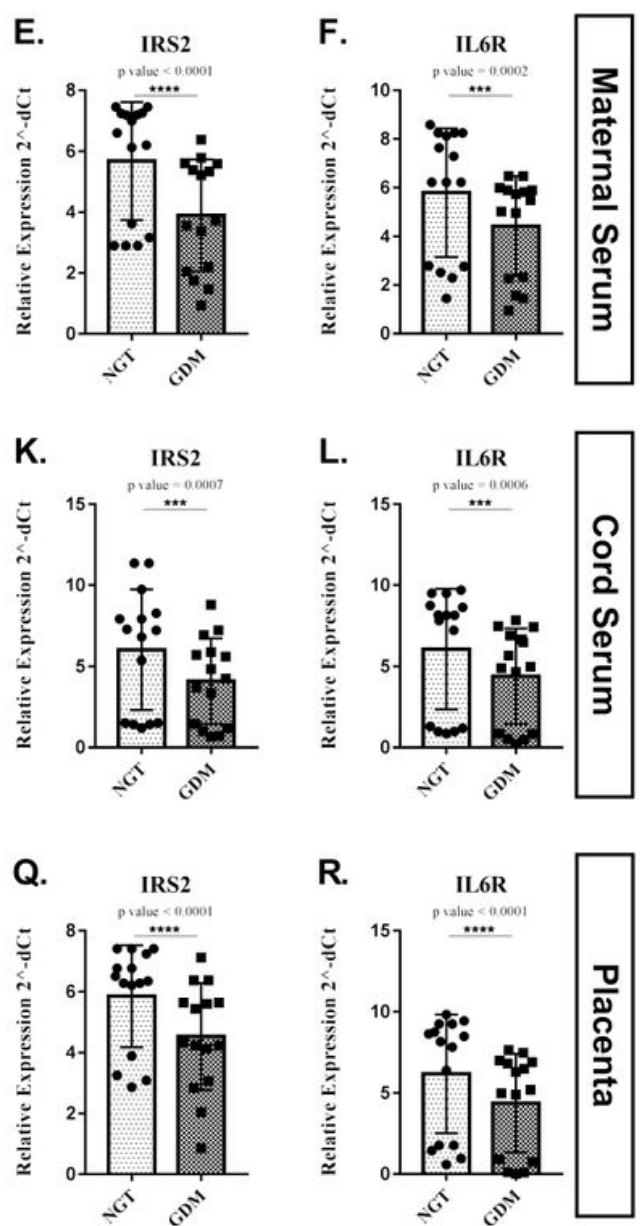

Figure 8

Figure legend not available with this version. 

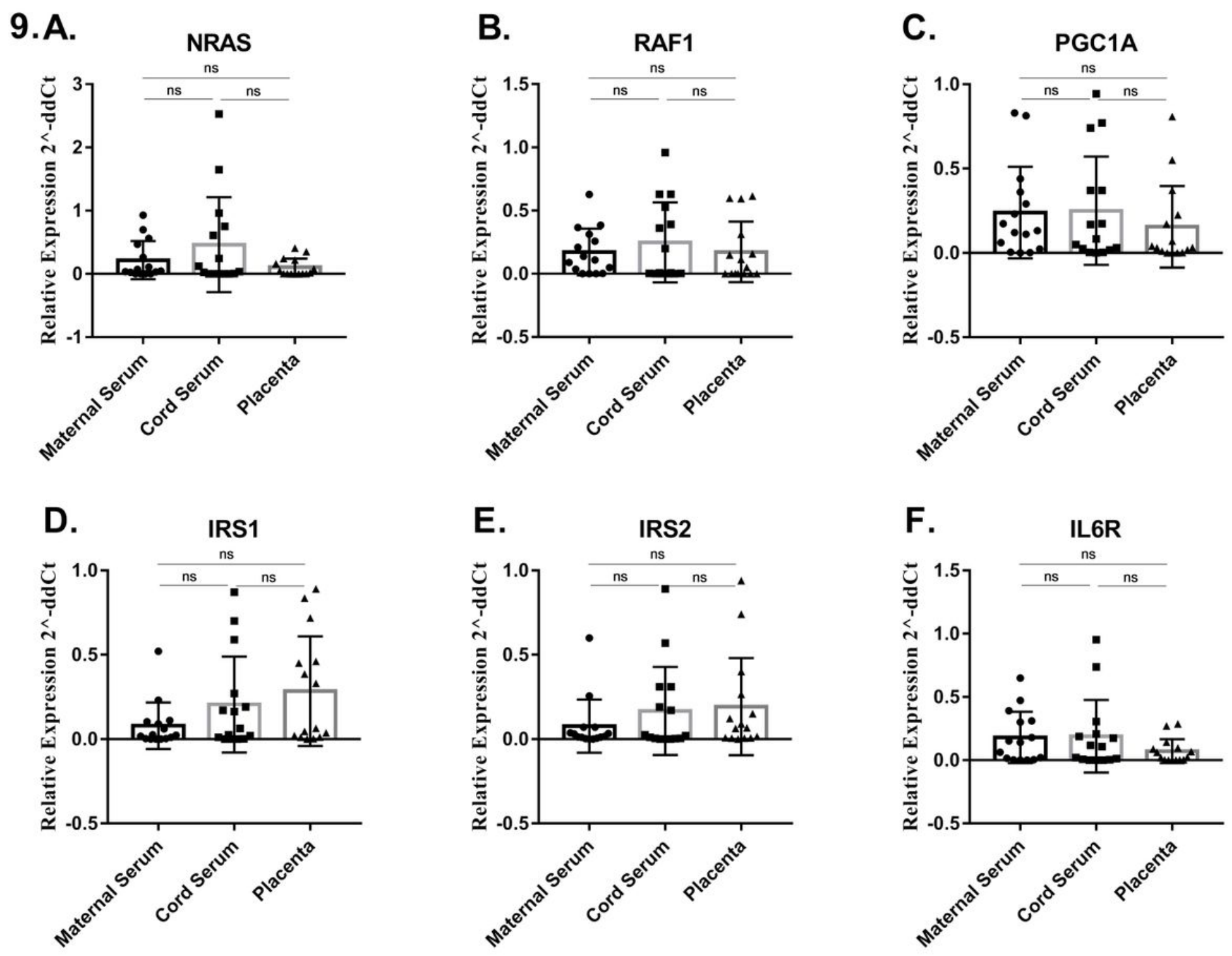

Figure 9

Figure legend not available with this version.

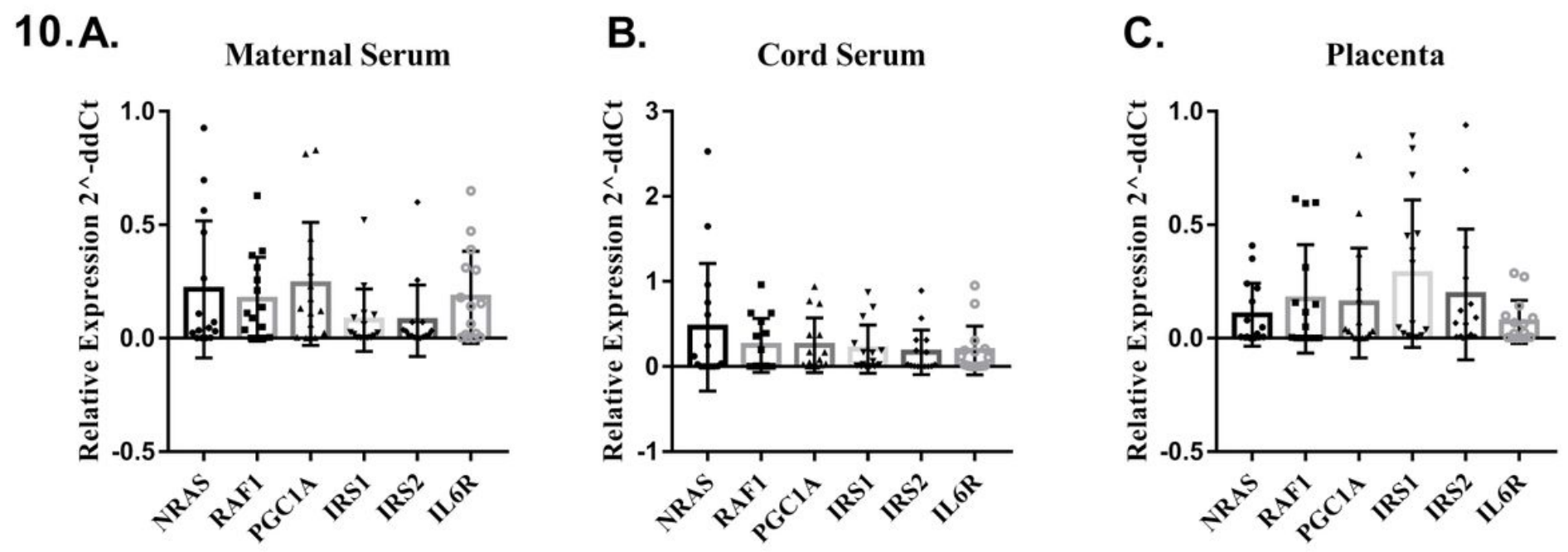


Figure 10

Figure legend not available with this version.

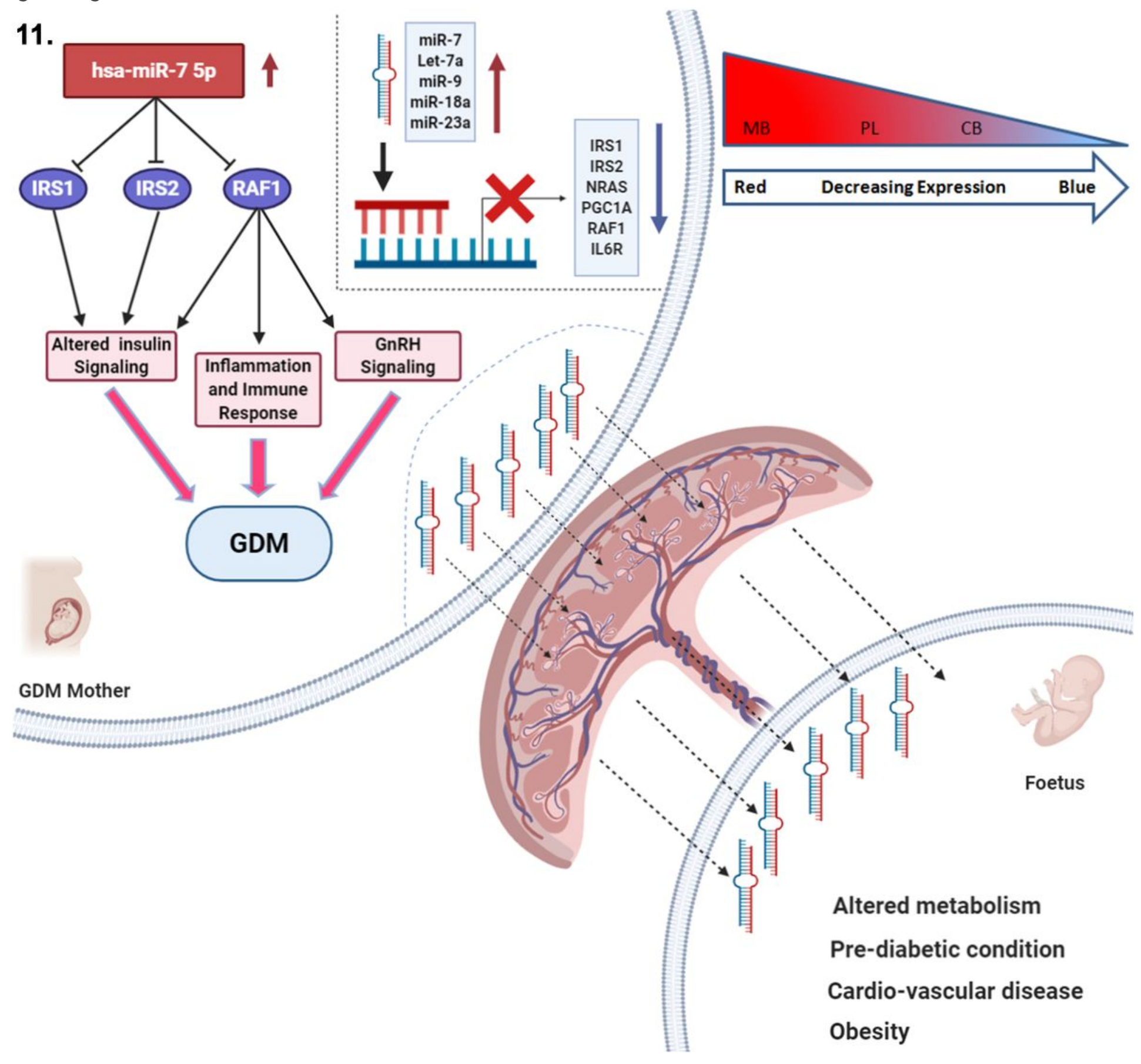

Figure 11

Figure legend not available with this version. 